\title{
BOUNDARY VALUE PROBLEMS FOR DIFFERENTIAL EQUATIONS WITH REFLECTION OF THE ARGUMENT
}

\author{
JOSEPH WIENER and A.R. AFTABIZADEH \\ Department of Mathematics \\ Pan American University \\ Edinburg, Texas 78539 \\ (Received July 30, 1984)
}

ABSTRACT. Linear and nonlinear boundary value problems for differential equations with reflection of the argument are considered.

KEY WORDS AND PHRASES. Functional Differential Equation, Boundary, Value Prohlems, Existence, Uniqueness.

1980 MATHEMATICS SUBJECT CLASSIFICATION CODE. 34 K10.

\section{INTRODUCTION.}

In [1-4] a method has been discovered for the study of functional differential equations whose argument deviations are involutions. Important in their own right, they have applications in the investigation of stability of differential-difference equations. Differential equations with involutions can be transformed by differentiation to higher order ordinary differential equations and, hence, admit of point data initial or boundary conditions. Initial value problems for such equations have been studied in numerous papers. However, boundary value problems even for differential equations with reflection of the argument have not been considered yet.

The purpose of this paper is to discuss existence and uniqueness of solutions

of

$$
y^{\prime \prime}=f(x, y(x), y(-x))
$$

where $f \in C[[-a, a] x R x R, R], a>0$, with the following types of boundary conditions

$$
y(-a)=y_{0} \cdot y(a)=y_{1}
$$

or

$$
y^{\prime}(-a)-h y(-a)=0, y^{\prime}(a)+k y(a)=0,
$$

where $\mathrm{h}, \mathrm{k}=0, \mathrm{~h}+\mathrm{k}>0$. 


\section{PRELIMINARY RESULTS.}

First, we prove a sequence of lemmas for the linear case,

$$
y^{\prime \prime}(x)=a(x) y(x)+b(x) y(-x)+c(x),
$$

which are needed in order to prove our results for the general equations of the form $(1.1)$.

Before we proceed further, we present some results without proof, which help to simplify the proofs of our results.

LEMMA 2.1. [5, pp.182]. If $y(0)=y(1)=0$ and $y(x) \varepsilon c^{1}[0,1]$, then

$$
\int_{0}^{1} y^{2}(x) d x \leq \frac{1}{\pi^{2}} \int_{0}^{1}\left[y^{\prime}(x)\right]^{2} d x
$$

LEMMA 2.2. [6]. If $\mathrm{f}(\mathrm{t}, \mathrm{x}, \mathrm{y})$ is continuous and has continuous first partials with respect to $x$ and $y$ on $[a, b] \times P$ where $P$ is an open convex set, then for $(t, x, y),(t, \bar{x}, \bar{y}) \varepsilon[a, b] x P$,

$$
f(t, x, y)-f(t, \bar{x}, \bar{y})=f_{2}(t, r(t), s(t))(x-\bar{x})+f_{3}(t, \bar{r}(t), \bar{s}(t))(y-\bar{y}),
$$

where

$$
f_{2}(t, r(t), s(t)) \equiv \int_{0}^{1} f_{2}(t, \tau x+(1-\tau) \bar{x}, \tau y+(1-\tau) \bar{y}) d \tau,
$$

and

$$
f_{3}(t, \bar{r}(t), \bar{s}(t)) \equiv \int_{0}^{1} f_{3}(t, \tau x+(1-\tau) \bar{x}, \tau y+(1-\tau) \bar{y}) d \tau,
$$

are continuous functions on $[a, b] \times P$ with $s(t), \bar{s}(t)$ between $y$ and $\bar{y}, r(t), \bar{r}(t)$ between $\mathrm{x}$ and $\overline{\mathrm{x}}$, and $0 \leq \tau \leq 1$.

LEMMA 2.3. The homogeneous boundary value problem

$$
u^{\prime \prime}=0 \text {, }
$$

together with

$$
u(a)=u(b)=0 \text {, }
$$

has the Green's function $G(x, t)$, defined by

$$
G(x, t)=-\frac{1}{b-a}\left\{\begin{array}{l}
(b-x)(t-a), a \leq t \leq x \leq b \\
(b-t)(x-a), a \leq x \leq t \leq b,
\end{array}\right.
$$

and the following estimates hold true:

$$
\int_{a}^{b}|G(x, t)| d t \leq \frac{(b-a)^{2}}{8}, \int_{a}^{b}\left|G_{x}(x, t)\right| d t \leq \frac{b-a}{2} .
$$

Now consider the second order linear differential equation 


$$
y^{\prime \prime}=a(x) y+b(x)
$$

with

$$
y^{\prime}(a)-h y(a)=0, y^{\prime}(b)+k y(b)=0, h, k \geq 0, h+k>0,
$$

where $a(x), b(x) \in c[[a, b], R]$. Then

LEMMA 2.4. [7]. Suppose $a(x) \geq m>0$ on $[a, b]$, then boundary value problem

(2.1) has a unique solution satisfying

$$
\sup |y(x)| \leq \frac{1}{m} \sup |b(x)|, \quad x \in[a, b] .
$$

\section{MAIN RESULTS.}

We are now in a position to state our results.

LEMMA 3.1. If $y(a)=y(b)=0$, and $y(x) \in c^{1}[a, b]$, then

$$
\int_{a}^{b} y^{2}(x) d x \leq \frac{(b-a)^{2}}{\pi^{2}} \int_{a}^{b}\left[y^{\prime}(x)\right]^{2} d x .
$$

PROOF. This follows easily from Lemma 2.1.

LEMMA 3.2. If $y(a)=y(b)=0$ and $y \in c^{1}[a, b]$, then

$$
\sup |y(x)| \leq \frac{\sqrt{b-a}}{2}\left[\int_{a}^{b}\left[y^{\prime}(x)\right]^{2} d x\right]^{1 / 2}, a \leq x \leq b
$$

PROOF. Since $y(a)=y(b)=0$, then one has

$$
2 y(x)=\int_{a}^{x} y^{\prime}(t) d t-\int_{x}^{b} y^{\prime}(t) d t,
$$

or

or

$$
2|y(x)| \leq \int_{a}^{x}\left|y^{\prime}(t)\right| d t+\int_{x}^{b}\left|y^{\prime}(t)\right| d t=\int_{a}^{b}\left|y^{\prime}(t)\right| d t,
$$

$$
\sup |y(x)| \leq \frac{1}{2} \int_{a}^{b}\left|y^{\prime}(t)\right| d t, a \leq x \leq b .
$$

Using the Cauchy-Schwartz inequality we have

$$
\sup |y(x)| \leq \frac{1}{2}\left[\int_{a}^{b} d t\right]^{1 / 2}\left[\int_{a}^{b}\left[y^{\prime}(t)\right]^{2} d t\right]^{1 / 2}, a \leq x \leq b .
$$

Thus

$$
\sup |y(x)| \leq \frac{\sqrt{b-a}}{2}\left[\int_{a}^{b}\left[y^{\prime}(x)\right]^{2} d x\right]^{1 / 2}, a \leq x \leq b
$$

LEMMA 3.3. Consider equation (2.1) with the boundary condition

$$
y(a)=y(b)=0,
$$


where $a(x) \geq-a_{0}>-\left(\frac{\pi}{b-a}\right)^{2}$. Then any solution $y(x)$ of (2.1) and (3.1) satisfies

$$
\sup |y(x)| \leq \frac{\pi(b-a)^{2}}{2\left[\pi^{2}-a_{0}(b-a)^{2}\right]} \quad \sup |b(x)|, a \leq x \leq b .
$$

PROOF. On multiplying (2.1) by $y(x)$, and integrating the result from a to $b$, we find, because of $(3.1)$,

$$
\int_{a}^{b}\left[y^{\prime}(x)\right]^{2} d x=-\int_{a}^{b} a(x) y^{2}(x) d x-\int_{a}^{b} b(x) y(x) d x,
$$

or

$$
\int_{a}^{b}\left[y^{\prime}(x)\right]^{2} d x \leq a_{0} \int_{a}^{b} y^{2}(x) d x+\sup |b(x)| \int_{a}^{b}|y(x)| d x
$$

Applying Lemma 3.1 and the Cauchy-Schwartz inequality, we get

$$
\int_{a}^{b}\left[y^{\prime}(x)\right]^{2} d x \leq \frac{a_{0}(b-a)^{2}}{\pi^{2}} \int_{a}^{b}\left[y^{\prime}(x)\right]^{2} d x+\frac{(b-a)^{3 / 2}}{\pi} \sup |b(x)|\left[\int_{a}^{b}\left[y^{\prime}(x)\right]^{2} d x\right]^{1 / 2}
$$

or

$$
\left[\int_{a}^{b}\left[y^{\prime}(x)\right]^{2} d x\right]^{1 / 2} \leq \frac{\pi(b-a)^{3 / 2}}{\pi^{2}-a_{0}(b-a)^{2}} \text { sup }|b(x)|, \quad a \leq x \leq b .
$$

Lemma 3.2 and the above inequality then imply inequality (3.2).

LEMMA 3.4. Suppose $a(x)$ and $b(x)$ satisfy all conditions of Lemma 3.3. Then problem (2.1) with the boundary conditions

$$
y(a)=y_{1}, y(b)=y_{2}
$$

has a unique solution.

PROOF. First, we show the uniqueness. Suppose $u(x)$ and $v(x)$ are solutions of (2.1), (3.2). Let $R(x)=u(x)-v(x)$, then

$$
R^{\prime \prime}(x)=a(x) R(x), \quad R(a)=R(b)=0 \text {. }
$$

By Lemma 3.3, $R(x) \equiv 0$, which implies $u(x)=v(x)$. So problem (2.1), (3.2) has a unique solution. To prove the existence, let $u(x)$ and $v(x)$ be solutions of the following initial value problems

$$
\begin{aligned}
\text { (i) } u^{\prime \prime}(x) & =a(x) u(x)+b(x), u(a)=y_{1}, u^{\prime}(a)=0 ; \\
\text { (ii) } v^{\prime \prime}(x) & =a(x) v(x), v(a)=0, v^{\prime}(a)=1 .
\end{aligned}
$$

We notice that $u(x)$ and $v(x)$ exist and are unique. Moreover, $v(b) \neq 0$, because if $v(b)=0$, then from $v(a)=0,(i i)$ and Lemma 3.3 we have $v(x) \equiv 0$ which contradicts $v^{\prime}(a)=1$. Therefore, by linearity,

$$
y(x)=u(x)+\frac{y_{2}-u(b)}{v(b)} v(x)
$$


defines the solution of the problem (2.1), (3.2). Proof is complete.

Let us now, consider the second order linear functional differential equation

$$
y^{\prime \prime}(x)=a(x) y(x)+b(x) y(-x)+c(x)
$$

where $a(x), b(x), c(x) \in c[-a, a], a>0$. We shall show that, under certain conditions on $a(x)$ and $b(x)$, equation (3.3) with a boundary condition has a unique solution on $[-a, a]$ and obtain an estimate for such solution.

LEMMA 3.5. Suppose that $a(x) \geq-m,|b(x)| \leq n, b(x) \neq 0, x \in[-a$, a], and $4 a^{2}(m+n)<\pi^{2}$. Then any solution of equation (3.3) with the boundary conditions

$$
y(a)=y(-a)=0 \text {, }
$$

satisfies

$$
\sup |y(x)| \leq \frac{2 \pi a^{2}}{\pi^{2}-4 a^{2}(m+n)} \sup |c(x)|, \quad-a \leq x \leq a .
$$

PROOF. On multiplying (3.3) by $y(x)$ and integrating the result from $-a$ to a we have

$$
\int_{-a}^{a}\left[y^{\prime}(x)\right]^{2} d x=-\int_{-a}^{a} a(x) y^{2}(x) d x-\int_{-a}^{a} b(x) y(x) y(-x) d x-\int_{-a}^{a} c(x) y(x) d x,
$$

or

$$
\int_{-a}^{a}\left[y^{\prime}(x)\right]^{2} d x \leq m \int_{-a}^{a} y^{2}(x) d x+n \int_{-a}^{a}|y(x)||y(-x)| d x+\sup |c(x)| \int_{-a}^{a}|y(x)| d x .
$$

Now, using Lemma 3.1, the Cauchy-Schwartz inequality, and the facts that

$$
|y(x)||y(-x)| \leq \frac{1}{2}\left[y^{2}(x)+y^{2}(-x)\right]
$$

and

$$
\int_{-a}^{a} y^{2}(x) d x=\int_{-a}^{a} y^{2}(-x) d x
$$

we obtain

$$
\left[\int_{-a}^{a}\left[y^{\prime}(x)\right]^{2} d x\right]^{1 / 2} \leq \frac{\pi(2 a)^{3 / 2}}{\pi^{2}-4 a^{2}(m+n)} \sup |c(x)|, \quad-a \leq x \leq a .
$$

Applying Lemma (3.2) and inequality (3.6) we get inequality (3.5).

Having Lemma 3.5, we can prove the following theorem.

THEOREM 3.1. In addition to the assumptions of Lemma 3.5 , suppose that $a(x)$ and $b(x)$ are even functions on $[-a, a]$. Then equation (3.3) with the boundary conditions

$$
y(-a)=y_{1}, y(a)=y_{2}
$$

has a unique solution. 
PROOF. Uniqueness follows from the fact that if $u(x)$ and $v(x)$ are two solutions of $(3.3),(3.7)$, then $R(x)=u(x)-v(x)$ implies

$$
\begin{aligned}
& R^{\prime \prime}(x)=a(x) R(x)+b(x) R(-x) \\
& \left.R_{j}^{\prime}-a\right)=R(a)=0 .
\end{aligned}
$$

Hence, from Lemma 3.5, $R(x) \equiv 0$ and $u(x)=v(x)$.

Now, we show that problem (3.3), (3.7) in fact has a solution. Let

$$
u(x)=y(x)-y(-x)
$$

Then

$$
u^{\prime \prime}(x)=y^{\prime \prime}(x)-y^{\prime \prime}(-x)
$$

From (3.3) and (3.9) we have

$$
u^{\prime \prime}(x)=a(x) y(x)+b(x) y(-x)-a(-x) y(-x)-b(-x) y(x)+c(x)-c(-x) \text {. }
$$

Since $a(x)$ and $b(x)$ are even, then

$$
u^{\prime \prime}(x)=a(x)[y(x)-y(-x)]-b(x)[y(x)-y(-x)]+c(x)-c(-x),
$$

or by $(3.8)$,

$$
u^{\prime \prime}(x)=[a(x)-b(x)] u(x)+c(x)-c(-x),
$$

and

$$
\mathrm{u}(-\mathrm{a})=\mathrm{y}_{1}-\mathrm{y}_{2}, \mathrm{u}(\mathrm{a})=\mathrm{y}_{2}-\mathrm{y}_{1}
$$

Problem (3.10), (3.11) is a form of (2.1), (3.2), then by Lemma 3.4 , it has a unique solution $u(x)$. Hence $y(-x)$ is given by

$$
y(-x)=y(x)-u(x) .
$$

This implies that

$$
y^{\prime \prime}(x)=[a(x)+b(x)] y(x)+c(x)-b(x) u(x)
$$

and

$$
y(-a)=y_{1}, y(a)=y_{2} \text {. }
$$

Again by Lemma 3.4, Problem (3.12), (3.13) has a unique solution which is the solution of (3.3), (3.7). Proof is complete.

Now consider the following second order linear functional differential equation

$$
y^{\prime \prime}(x)=a(x) y(-x)+b(x)
$$

where $a(x) \neq 0$ on $[-a, a]$. By differentiation and algebraic elimination this equation can be reduced to the fourth order differential equation

$$
y^{(4)}(x)=A(x) y^{\prime \prime \prime}(x)+B(x) y^{\prime \prime}(x)+C(x) y(x)+D(x), x \varepsilon[-a, a],
$$

where 


$$
\begin{aligned}
& A(x)=\frac{2 a^{\prime}(x)}{a(x)}, \\
& B(x)=\left[\frac{a^{\prime}(x)}{a(x)}\right]^{\prime}-\left[\frac{a^{\prime}(x)}{a(x)}\right]^{2}=\frac{1}{2} a^{\prime}(x)-\frac{1}{4} a^{2}(x), \\
& C(x)=a(x) a(-x) \\
& D(x)=a(x)\left[b(-x)+\left[\frac{b(x)}{a(x)}\right]^{\prime \prime}\right]
\end{aligned}
$$

By a solution of (3.14) we mean a solution that is four times differentlable.

We shall show that equation (3.15) with the boundary conditions

$$
y(-a)=A_{1}, y(a)=A_{2}, y^{\prime \prime}(-a)=B_{1}, y^{\prime \prime}(a)=B_{2}
$$

has a unique solution. We use the method given by R. A. Usmani [8]. First we need the following Lemma.

LEMMA 3.6. Consider the fourth order linear differential equation (3.15) with the boundary condition

$$
y(-a)=y(a)=y^{\prime \prime}(-a)=y^{\prime \prime}(a)=0,
$$

where $A(x) \in C^{1}[-a, a], B(x), C(x), D(x) \varepsilon C[-a, a], \frac{1}{2} A^{\prime}(x)-B(x) \leq m$ and $|c(x)| \leq n$. If

$$
4 m \pi^{2} a^{2}+16 n a^{4}<\pi^{4}
$$

then any solution of (3.15), (3.17) satisfies

$$
\sup |y(x)| \leq \frac{8 \pi a^{4}}{\pi^{4}-4 m \pi^{2} a^{2}-16 n a^{4}} \sup |D(x)|,-a \leq x \leq a .
$$

PROOF. Let

$$
y^{\prime \prime}=z \text {. }
$$

On multiplying $(3.20)$ by $y(x)$ and integrating the result from $-a$ to $a$, we have

$$
\int_{-a}^{a}\left[y^{\prime}(x)\right]^{2} d x=-\int_{-a}^{a} y z d x
$$

or

$$
\int_{-a}^{a}\left[y^{\prime}(x)\right]^{2} d x \leq\left[\int_{-a}^{a} y^{2}(x) d x\right]^{1 / 2}\left[\int_{-a}^{a} z^{2}(x) d x\right]^{1 / 2} .
$$

Applying Lemma 3.1, we obtain

$$
\left[\int_{-a}^{a}\left[y^{\prime}(x)\right]^{2} d x\right]^{1 / 2} \leq \frac{4 a^{2}}{\pi^{2}}\left[\int_{-a}^{a}\left[z^{\prime}(x)\right]^{2} d x\right]^{1 / 2} \text {. }
$$

Also, from $(3,20)$ and (3.15) 


$$
\begin{gathered}
z^{\prime \prime}=A(x) z^{\prime}+B(x) z+C(x) y+D(x), \\
z(-a)=z(a)=0 .
\end{gathered}
$$

In a similar manner,

$$
\left[\int_{-a}^{a}\left[z^{\prime}(x)\right]^{2} d x\right]^{1 / 2} \leq \frac{\pi^{3}(2 a)^{3 / 2}}{\pi^{4}-4 m a^{2} \pi^{2}-16 n a^{4}} \sup |D(x)|,-a \leq x \leq a .
$$

From Lemma 3.2, (3.21) and (3.23) inequality (3.19) follows.

THEOREM 3.2. Suppose all assumptions of Lemma 3.6 hold true. Then problem (3.15), (3.16) has a unique solution.

PROOF. Assume that there exist two distinct functions $u(x)$ and $v(x)$ satisfying (3.15) and (3.16). Then it is easily seen that $\psi(x)=u(x)-v(x)$ satisfies

$$
\psi^{(4)}(\mathrm{x})=\mathrm{A}(\mathrm{x}) \psi^{\prime \prime \prime}(\mathrm{x})+\mathrm{B}(\mathrm{x}) \psi^{\prime \prime}(\mathrm{x})+\mathrm{C}(\mathrm{x}) \psi(\mathrm{x}), \psi(-\mathrm{a})=\psi(\mathrm{a})=\psi^{\prime \prime}(-\mathrm{a})=\psi^{\prime \prime}(\mathrm{a})=0 .(3.24)
$$

Now, from Lemma 3.6 and (3.24) it follows that $\sup |\psi(x)| \leq 0$, which proves $\psi(x) \equiv 0$ and $u(x)=v(x)$ on $[-a, a]$. This shows that problem $(3.15),(3.16)$ has at most one solution.

In order to prove that $(3.15),(3.16)$ indeed has a solution, we define functions $y_{1}(x), 1=1, \ldots, 4$, as solutions of the respective initial value problems:

$$
y_{1}^{(4)}=A(x) y_{1}^{\prime \prime \prime}+B(x) y_{1}^{\prime \prime}+C(x) y_{1}+D(x), y_{1}(-a)=A_{1}, \quad y_{1}^{\prime}(-a)=y_{1}^{\prime \prime}(-a)=y_{1}^{\prime \prime \prime}(-a)=0
$$$$
\text { (ii) } \quad y_{2}^{(4)}=A(x) y_{2}^{\prime \prime \prime}+B(x) y_{2}^{\prime \prime}+C(x) y_{2}, \quad y_{2}^{\prime}(-a)=1, \quad y_{2}(-a)=y_{2}^{\prime \prime}(-a)=y_{2}^{\prime \prime \prime}(-a)=0 \text {; }
$$$$
\text { (111) } y_{3}^{(4)}=A(x) y_{3}^{\prime \prime \prime}+B(x) y_{3}^{\prime \prime}+C(x) y_{3}, \quad y_{3}^{\prime \prime}(-a)=B_{1}, \quad y_{3}(-a)=y_{3}^{\prime}(-a)=y_{3}^{\prime \prime \prime}(-a)=0 \text {; }
$$

(iv) $\quad y_{4}^{(4)}=A(x) y_{4}^{\prime \prime \prime}+B(x) y_{4}^{\prime \prime}+C(x) y_{4}, \quad y_{4}^{\prime \prime \prime}(-a)=1, \quad y_{4}(-a)=y_{4}^{\prime}(-a)=y_{4}^{\prime \prime}(-a)=0$.

From the continuity of $A(x), B(x), C(x)$, and $D(x)$ we are assured that unique solutions of these initial value problems exist on $[-a, a]$. Furthermore, the function

$$
z(x)=y_{1}(x)+s y_{2}(x)+y_{3}(x)+t y_{4}(x) \text {, }
$$

$s$, $t$ being scalars, satisfies the inftial value problem

$$
z^{(4)}=A(x) z^{\prime \prime \prime}+B(x) z^{\prime \prime}+C(x) z+D(x), z(-a)=A_{1}, z^{\prime}(-a)=s, z^{\prime \prime}(-a)=B_{1}, z^{\prime \prime \prime}(-a)=t
$$

The function $z(x)$ will be a solution of (3.15), (3.16) provided $s, t$ satisfy

$$
\begin{aligned}
& s y_{2}(a)+t y_{4}(a)=A_{2}-y_{1}(a)-y_{3}(a), \\
& s y_{2}^{\prime \prime}(a)+t y_{4}^{\prime \prime}(a)=B_{2}-y_{1}^{\prime \prime}(a)-y_{3}^{\prime \prime}(a) .
\end{aligned}
$$

If $\Delta=y_{2}(a) y_{4}^{\prime \prime}(a)-y_{2}^{\prime \prime}(a) y_{4}(a) \neq 0$, a unique solution of the preceding linear 
system can be found, and the corresponding function $z(x)$ then is the unique solution of $(3.15),(3.16)$. However, if $\Delta=0$, then

$$
\frac{y_{2}(a)}{y_{2}^{\prime \prime}(a)}=\frac{y_{4}(a)}{y_{4}^{\prime \prime}(a)}=p \text { (constant). }
$$

We can assume that $p \neq 0$, because if $p=0$, then $y_{2}(a)=0$ and by means of Taylor's formula it can be shown that the solution of

$$
y_{2}^{(4)}=A(x) y_{2}^{\prime \prime \prime}+B(x) y_{2}^{\prime \prime}+C(x) y_{2}, y_{2}(a)=y_{2}^{\prime \prime}(-a)=y_{2}^{\prime \prime \prime}(-a)=y_{2}(-a)=0
$$

has the property $y_{2}^{\prime}(-a)=0$, contradicting the original assumption $y_{2}^{\prime}(-a)=1$. Similarly, p cannot be unbounded. Thus it follows that

$$
y_{2}(a)=p y_{2}^{\prime \prime}(a), p<\infty \text {. }
$$

Now using (ii), and the Taylor formula, we obtain

$$
\begin{gathered}
y_{2}(a)=2 a+\frac{2}{3} a^{4}\left[A(\alpha) y_{2}^{\prime \prime \prime}(\alpha)+B(\alpha) y_{2}^{\prime \prime}(\alpha)+C(\alpha) y_{2}(\alpha)\right],-a<\alpha<a, \\
y_{2}^{\prime \prime}(a)=2 a^{2}\left[A(\beta) y_{2}^{\prime \prime \prime}(\beta)+B(\beta) y_{2}^{\prime \prime}(\beta)+C(\beta) y_{2}(\beta)\right],-a<\beta<a .
\end{gathered}
$$

On combining (3.25) and (3.26) we get

$$
\operatorname{ap}\left[A(\beta) y_{2}^{\prime \prime \prime}(\beta)+B(\beta) y_{2}^{\prime \prime}(\beta)+C(\beta) y_{2}(\beta)\right]-\frac{1}{3} a^{3}\left[A(\alpha) y_{2}^{\prime \prime \prime}(\alpha)+B(\alpha) y_{2}^{\prime \prime}(\alpha)+C(\alpha) y_{2}(\alpha)\right]=1 \text {, }
$$

for al1 $\mathrm{A}(\mathrm{x}), \mathrm{B}(\mathrm{x}), \mathrm{C}(\mathrm{x}) \in \mathrm{C}[-\mathrm{a}, \mathrm{a}]$. In an attempt to determine $\mathrm{y}_{2}(\alpha), \mathrm{y}_{2}(f), \mathrm{y}_{2}^{\prime \prime}(\alpha)$, $y_{2}^{\prime \prime}(\beta), y_{2}^{\prime \prime \prime}(\alpha)$ and $y_{2}^{\prime \prime \prime}(\beta)$, we choose

$$
\begin{aligned}
& \mathrm{A}(\mathrm{x})=1, \mathrm{~B}(\mathrm{x})=1, \mathrm{C}(\mathrm{x})=1, \\
& \mathrm{~A}(\mathrm{x})=1, \mathrm{~B}(\mathrm{x})=1, \mathrm{C}(\mathrm{x})=-1, \\
& \mathrm{~A}(\mathrm{x})=-1, \mathrm{~B}(\mathrm{x})=-1, \mathrm{C}(\mathrm{x})=1, \\
& \mathrm{~A}(\mathrm{x})=-1, \mathrm{~B}(\mathrm{x})=-1, \mathrm{C}(\mathrm{x})=-1, \\
& \mathrm{~A}(\mathrm{x})=1, \mathrm{~B}(\mathrm{x})=-1, \mathrm{C}(\mathrm{x})=1, \\
& \mathrm{~A}(\mathrm{x})=1, \mathrm{~B}(\mathrm{x})=-1, \mathrm{C}(\mathrm{x})=-1,
\end{aligned}
$$

giving the system

$$
\begin{aligned}
& \operatorname{ap}\left[y_{2}^{\prime \prime \prime}(\beta)+y_{2}^{\prime \prime}(\beta)+y_{2}(\beta)\right]-\frac{1}{3} a^{3}\left[y_{2}^{\prime \prime \prime}(\alpha)+y_{2}^{\prime \prime}(\alpha)+y_{2}(\alpha)\right]=1, \\
& \operatorname{ap}\left[y_{2}^{\prime \prime \prime}(\beta)+y_{2}^{\prime \prime}(\beta)-y_{2}(\beta)\right]-\frac{1}{3} a^{3}\left[y_{2}^{\prime \prime \prime}(\alpha)+y_{2}^{\prime \prime}(\alpha)-y_{2}(\alpha)\right]=1, \\
& \operatorname{ap}\left[-y_{2}^{\prime \prime \prime}(\beta)-y_{2}^{\prime \prime}(\beta)+y_{2}(\beta)\right]-\frac{1}{3} a^{3}\left[-y_{2}^{\prime \prime \prime}(\alpha)-y_{2}^{\prime \prime}(\alpha)+y_{2}(\alpha)\right]=1, \\
& \operatorname{ap}\left[-y_{2}^{\prime \prime \prime}(\beta)-y_{2}^{\prime \prime}(\beta)-y_{2}(\beta)\right]-\frac{1}{3} a^{3}\left[-y_{2}^{\prime \prime \prime}(\alpha)-y_{2}^{\prime \prime}(\alpha)-y_{2}(\alpha)\right]=1, \\
& \operatorname{ap}\left[y_{2}^{\prime \prime \prime}(\beta)-y_{2}^{\prime \prime}(\beta)+y_{2}(\beta)\right]-\frac{1}{3} a^{3}\left[y_{2}^{\prime \prime \prime}(\alpha)-y_{2}^{\prime \prime}(\alpha)+y_{2}(\alpha)\right]=1,
\end{aligned}
$$




$$
\operatorname{ap}\left[y_{2}^{\prime \prime \prime}(\beta)-y_{2}^{\prime \prime}(\beta)-y_{2}(\beta)\right]-\frac{1}{3} a^{3}\left[y_{2}^{\prime \prime \prime}(\alpha)-y_{2}^{\prime \prime}(\alpha)-y_{2}(\alpha)\right]=1 \text {. }
$$

But this latter system in the unknowns $y_{2}(\alpha), y_{2}(\beta), \ldots$ is inconsistent. We thus conclude that $\Delta$ cannot vanish and the proof of the theorem is completed.

Now, it is easy to show that problem (3.14) with $y(-a)=y(a)=0$ has a unique solution.

THEOREM 3.3. Consider equation $(3.14)$. Suppose $a(x) \in C^{(2)}[-a, a] b(x) \varepsilon$ $c[-a, a], b(-a)=b(a)=0,\left[\frac{a^{\prime}(x)}{a(x)}\right]^{2} \leq m$ and $|a(x) a(-x)| \leq n$.

If

$$
4 m \pi^{2} a^{2}+16 n a^{4}<\pi^{4}
$$

then equation ( 3.14$)$ with

$$
y(-a)=y(a)=0
$$

has a unique solution.

PROOF. Since equation (3.14) can be reduced to equation (3.15), then by theorem 3.2, problem (3.14), (3.27) has a unique solution.

Now, we consider the general equation (1.1) and prove the following theorems.

THEOREM 3.4. Suppose $f$ is bounded on $[-a, a] x R x R$. Then problem $(1.1),(1.2)$ has a solution.

PROOF. Problem $(1.1),(1.2)$ is equivalent to

$$
y(x)=\frac{1}{2}\left(y_{1}+y_{0}\right)+\frac{1}{2 a}\left(y_{1}-y_{0}\right) x+\int_{-a}^{a} G(x, t) f(t, y(t), y(-t)) d t,
$$

where $G(x, t)$ is given by Lemma 2.3. Let $M$ be the bound of $|f|$ on $[-a, a] x R x$. Define a mapping $\mathrm{T}: \mathrm{E} \rightarrow \mathrm{E}$ by

$$
\operatorname{Ty}(x)=\frac{1}{2}\left(y_{1}+y_{0}\right)+\frac{1}{2 a}\left(y_{1}-y_{0}\right) x+\int_{-a}^{a} G(x, t) f(t, y(t), y(-t)) d t,
$$

where $E=C[[-a, a], R]$ is a Banach space with the norm

$$
|| y||_{E}=\max |y(x)|,-a \leq x \leq a .
$$

Then from (3.29) and the estimates on $G(x, t)$ and $G_{x}(x, t)$, it follows that

$$
|\mathrm{Ty}(\mathrm{x})| \leq \frac{1}{2}\left|\mathrm{y}_{1}+\mathrm{y}_{0}\right|+\frac{1}{2 \mathrm{a}}\left|\mathrm{y}_{1}-\mathrm{y}_{0}\right|+\frac{1}{2} \mathrm{a}^{2} \mathrm{M}
$$

and

$$
\left|T^{\prime} y(x)\right| \leq \frac{1}{2 a}\left|y_{1}-y_{0}\right|+a M .
$$

Hence, $\mathrm{T}$ maps the closed, bounded, and convex set

$$
B=\left\{y \in E:|y(x)| \leq \frac{1}{2}\left|y_{1}+y_{0}\right|+\frac{1}{2 a}\left|y_{1}-y_{0}\right|+\frac{1}{2} a^{2} M\right\}
$$


into itself. Moreover, since $T^{\prime} y(x)$ verifies (3.31), $T$ is completely continuous on $C[[-a, a], R]$ by Ascoli's theorem. The Schauder's fixed point theorem then yields a fixed point of $\mathrm{T}$, which is a solution of (1.1), (1.2), thus completing the proof of the theorem.

THEOREM 3.5. Suppose $f$ is continuous and for $(x, y, z),(x, \bar{y}, \bar{z}) \varepsilon[-a, a] x R R$, it satisfies a Lipschitz condition

$$
|f(x, y, z)-f(x, \bar{y}, \bar{z})| \leq L_{1}|y-\bar{y}|+L_{2}|z-\bar{z}|,
$$

where $\mathrm{L}_{1}$ and $\mathrm{L}_{2}>0$. Then the boundary value problem (1.1), (1.2) has a unique solution, provided

$$
a^{2}\left(L_{1}+L_{2}\right)<2
$$

PROOF. Let $B$ be the Banach space of functions y $\varepsilon c[[-a, a], R]$ with the norm

$$
\|\mathrm{y}\|_{\mathrm{B}}=\max |\mathrm{y}(\mathrm{x})|,-\mathrm{a} \leq \mathrm{x} \leq \mathrm{a} \text {. }
$$

Define the operator $T: B \rightarrow B$ by (3.29). Then for $y_{1}(x)$ and $y_{2}(x) \varepsilon B$, we have

$$
\left|\mathrm{Ty}_{1}(x)-\mathrm{Ty}_{2}(x)\right| \leq \int_{-a}^{a}|G(x, t)|\left|f\left(t, y_{1}(t), y_{1}(-t)\right)-f\left(t, y_{2}(t), y_{2}(-t)\right)\right| d t .
$$

Using the Lipschitz condition (3.32) we obtain

$$
\left|\mathrm{Ty}_{1}(x)-\mathrm{Ty}_{2}(x)\right| \leq \int_{-a}^{a}|G(x, t)|\left[L_{1}\left|y_{1}(t)-y_{2}(t)\right|+L_{2}\left|y_{1}(-t)-y_{2}(-t)\right|\right] d t,
$$

or

$$
\left|\mathrm{Ty}_{1}(x)-\mathrm{Ty}_{2}(\mathrm{x})\right| \leq \frac{\mathrm{a}^{2}\left(\mathrm{~L}_{1}+\mathrm{L}_{2}\right)}{2} \max \left|\mathrm{y}_{1}(\mathrm{x})-\mathrm{y}_{2}(\mathrm{x})\right|,-\mathrm{a} \leq \mathrm{x} \leq \mathrm{a},
$$

or

$$
\left\|\mathrm{Ty}_{1}(\mathrm{x})-\mathrm{Ty}_{2}(\mathrm{x})\right\|_{\mathrm{B}} \leq \frac{\mathrm{a}^{2}\left(\mathrm{~L}_{1}+\mathrm{L}_{2}\right)}{2}\left\|\mathrm{y}_{1}(\mathrm{x})-\mathrm{y}_{2}(\mathrm{x})\right\|_{\mathrm{B}}
$$

Also,

$$
\left\|T^{\prime} y_{1}(x)-T^{\prime} y_{2}(x)\right\|\left\|_{B} \leq a\left(L_{1}+L_{2}\right)\right\| y_{1}(x)-y_{2}(x) \|_{B} \text {. }
$$

Al1 of these considerations and inequality (3.33) show that $T$ is a contraction mapping and thus has a unique fixed point which is the solution of $(1.1),(1.2)$. Proof is complete.

THEOREM 3.6. Assume that there exist positive numbers $m$ and $r$ such that

(i) $\sup |f(x, 0, y)| \leq \frac{\pi^{2}-4 m a^{2}}{2 \pi a^{2}} r$, for $x \in[-a, a],|y| \leq r$,

(ii) $f(x, y, z)$ has a continuous partial derivative with respect to $y$ on $[-a, a] \times R \times R$ and 


$$
f_{2}(x, y, z) \geq-m>\frac{-\pi^{2}}{4 a^{2}} \text {, for } x \in[-a, a], y \in R,|z| \leq r
$$

Then equation (1.1) with the boundary conditions

$$
y(-a)=y(a)=0,
$$

has a solution.

PROOF. Let $B_{r}=\{y \in C[-a, a]:|y| \leq r\}$. For $y \in B_{r}$ and $x \in[-a$, a $]$, define a mapping $\mathrm{T}: \mathrm{C}[-\mathrm{a}, \mathrm{a}] \rightarrow \mathrm{C}[-\mathrm{a}, \mathrm{a}]$ by $(\mathrm{Ty})(\mathrm{x})=\mathrm{v}(\mathrm{x})$, where

$$
v^{\prime \prime}(x)=f(x, v(x), y(-x)) \text {, }
$$

and

$$
v(-a)=v(a)=0 .
$$

Equation (3.35) is equivalent to

$$
v^{\prime \prime}(x)=f(x, v(x), y(-x))-f(x, 0, y(-x))+f(x, 0, y(-x)) .
$$

Then from Lemma 2.2 , it follows that

$$
v^{\prime \prime}(x)=\left(\int_{0}^{1} f_{2}[x, \tau v(x), y(-x)] d \tau\right) v(x)+f(x, 0, y(-x)) .
$$

Applying Lemma 3.3 and condition (ii) we have

or from (i)

$$
\sup |v(x)| \leq \frac{2 \pi a^{2}}{\pi^{2}-4 m a^{2}} \sup |f(x, 0, y(-x))|,-a \leq x \leq a,
$$

$$
\sup |\mathrm{v}(\mathrm{x})| \leq \mathrm{r}, \quad-\mathrm{a} \leq \mathrm{x} \leq \mathrm{a} .
$$

Hence, $T$ maps the closed, bounded, and convex set $B_{r}$ into itself. Moreover, from $(3.35),(3.36)$ and Lemma 2.3

$$
v(x)=\int_{-a}^{a} G(x, t) f(t, v(t), y(-t)) d t,
$$

or

$$
v^{\prime}(x)=\int_{-a}^{a} G_{x}(x, t) f(t, v(t), y(-t)) d t
$$

Since $|f(x, v(x), y(-x))| \leq k$, for $x \in[-a, a],|v(x)| \leq r,|y(-x)| \leq r$, then

$$
\left|v^{\prime}(x)\right| \leq a k \text {. }
$$

All of these considerations show that $T$ is completely continuous by Ascoli's theorem. Schauder's fixed point theorem then yields a fixed point of $T$, which is a solution of $(1.1),(3.34)$.

THEOREM 3.7. Assume that there exist positive numbers $m$ and $\mathbf{r}$ such that

(i) $\sup |f(x, 0, y)| \leq m r$, for $x \in[-a, a],|y| \leq r$,

(ii) $f(x, y, z)$ has a continuous partial derivative with respect to $y$ on $[-a$, $a] \times R \times R$ and 


$$
\mathrm{f}_{2}(\mathrm{x}, \mathrm{y}, \mathrm{z}) \geq \mathrm{m}>0, \text { for } \mathrm{x} \in[-\mathrm{a}, \mathrm{a}], \mathrm{y} \in \mathrm{R},|\mathrm{z}| \leq \mathrm{r}
$$

Then the boundary value problem (1.1), (1.3) has a solution.

PROOF. Let ${ }^{B}{ }_{r}=\{y \in C[-a, a]:|y| \leq r\}$. For $y \in B_{r}$, define a mapping $\mathrm{T}: \mathrm{C}[-\mathrm{a}, \mathrm{a}]+\mathrm{C}[-\mathrm{a}, \mathrm{a}]$ by $(\mathrm{Ty})(\mathrm{x})=\mathrm{v}(\mathrm{x})$, where

$$
\begin{aligned}
& v^{\prime \prime}=f(x, v(x), y(-x)) \\
& v^{\prime}(-a)-h v(-a)=0, v^{\prime}(a)+k v(a)=0 .
\end{aligned}
$$

Equation (3.40) is equivalent to

$$
v^{\prime \prime}=\left(\int_{0}^{1} f_{2}[x, \tau v(x), y(-x)] d \tau\right) v(x)+f(x, 0, y(-x)) .
$$

Using Lemma 3.3 and conditions (i), (ii) we obtain

$$
\sup |v(x)| \leq r, \quad-a \leq x \leq a \text {. }
$$

This shows that $T$ maps ${ }_{r}$ into itself. Also from $(3,40)$ we have

$$
v^{\prime}(x)=v^{\prime}(-a)+\int_{-a}^{x} f[t, v(t), y(-t)] d t .
$$

Since $v^{\prime}(-a)=h v(-a)$, then $\left|v^{\prime}(-a)\right| \leq h|v(-a)| \leq h r$. Moreover, $|f(x, y, z)| \leq k$ for $\mathrm{x} \varepsilon[-\mathrm{a}, \mathrm{a}],|\mathrm{y}| \leq \mathrm{r},|\mathrm{z}| \leq \mathrm{r}$, then

$$
\left|v^{\prime}(x)\right| \leq h r+2 a k
$$

Thus, $T$ is completely continuous by Ascoli's theorem. Schauder's fixed point theorem then yields a fixed point of $T$, which is a solution of $(1.1),(1.3)$.

ACKNOWLEDGEMENT. Research partially supported by U.S. Army Grant 非DAAG29-84-G-0034

\section{REFERENCES}

1. PRZEWORSKA-ROLEWICZ, D. Equations with Transformed Argument, An Algebraic Approach, Panstwowe Wydawnictvo Naukowe, Warszawa, (1973).

2. WIENER, J. Differential equations with involutions, Differencial'nye Uravnenija 6, (1969), 1131-1137.

3. WIENER, J. Differential equations with periodic transformations of the argument. Izv. Vyss. Ucebn. Zaved. Radiofizika, 3, (1973), 481-489.

4. WIENER, J. Periodic maps in the study of functional differential equations, Differentcial'nye Uravnenija (Iryazan), 3 , (1974), 34-45.

5. HARDY, G.H., LITTLEWOOD, J.E., and POLYA, G. Inequalities, Cambridge Univ. Press, London and New York, 1952.

6. BEBERNES, J.W. and GAINES, R. Dependence on boundary data and a generalized boundary-value problem, J. Differential Equations, 4, (1968), 359-368.

7. CORDUNEANU, C. Sopra I problemi ai limiti per alcuni sistemi di equazioni differenziali non lineari, Rendiconto Academia Napoli, (1958), 98-106.

8. USMANI, R.A. A uniqueness theorem for a boundary value problem, Proc. Am. Math. Society, vo1. 77, no. 3, Dec. (1979), 329-335. 


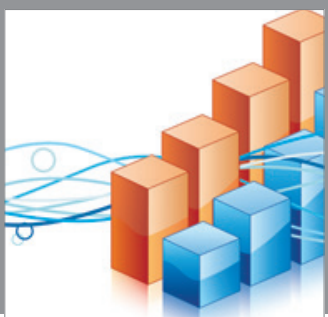

Advances in

Operations Research

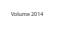

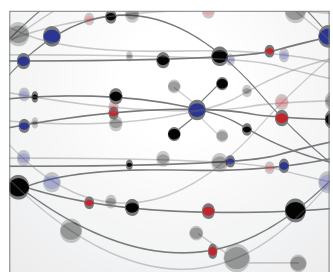

\section{The Scientific} World Journal
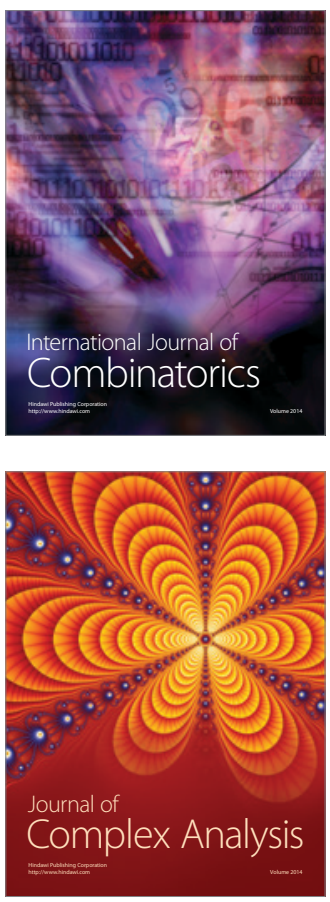

International Journal of

Mathematics and

Mathematical

Sciences
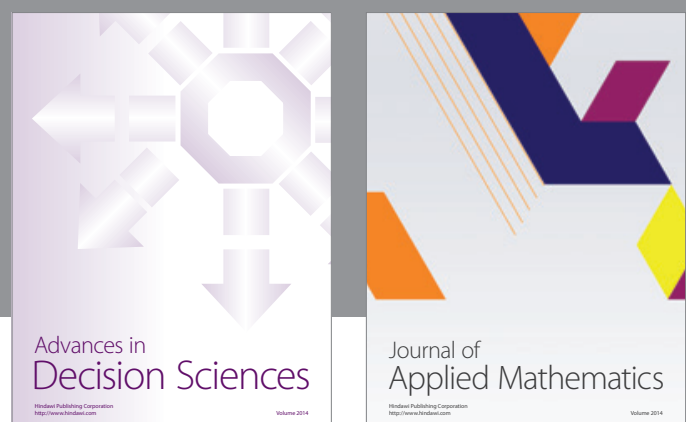

Journal of

Applied Mathematics
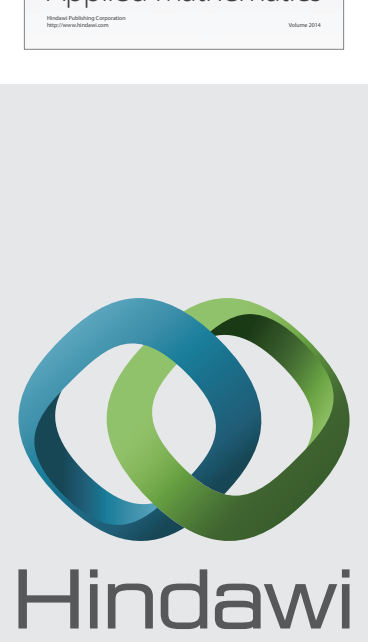

Submit your manuscripts at http://www.hindawi.com
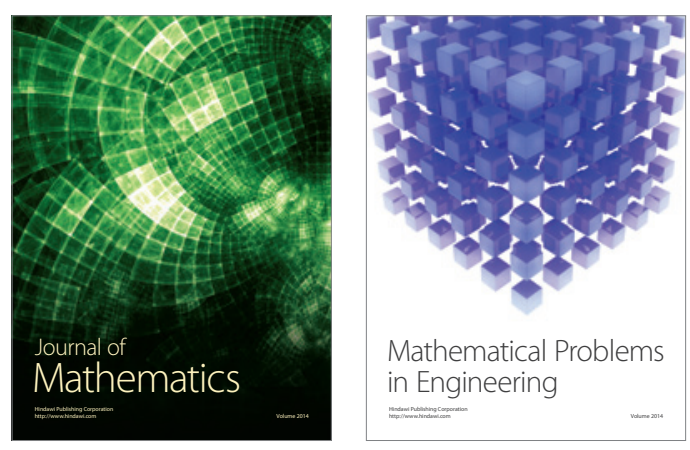

Mathematical Problems in Engineering
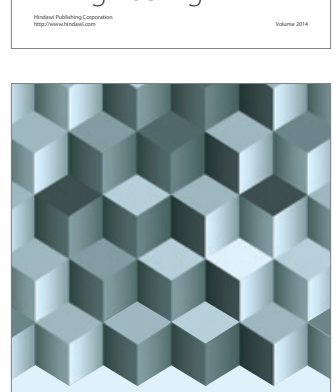

Journal of

Function Spaces
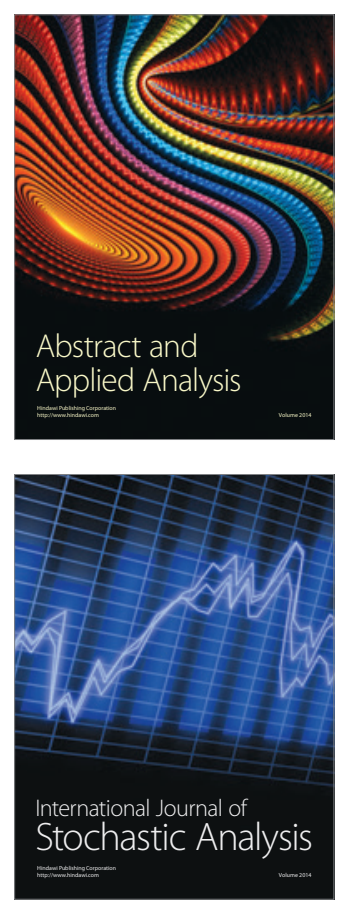

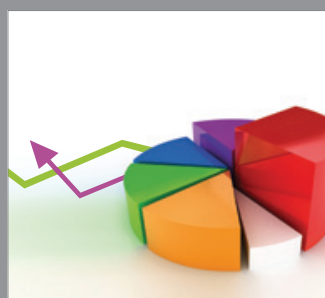

ournal of

Probability and Statistics

Promensencen
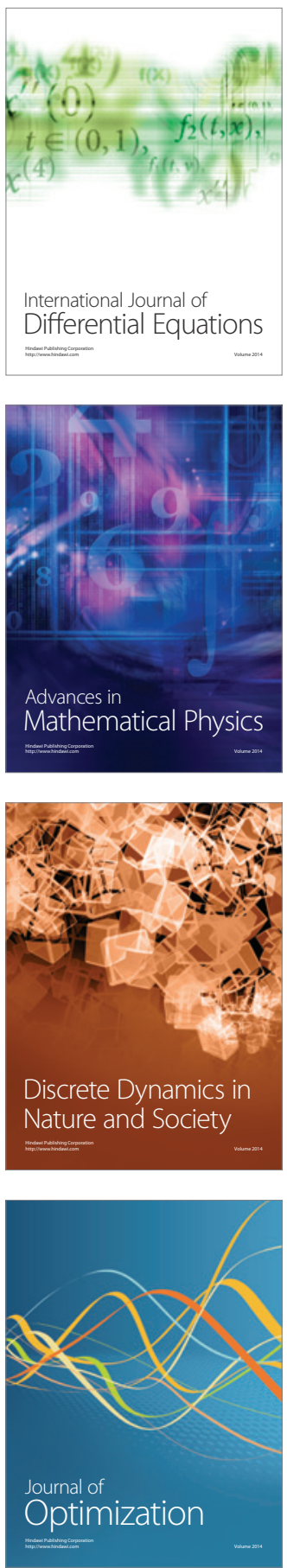